\title{
A prospective study of two isothermal amplification assays compared with real- time PCR, CCNA and toxigenic culture for the diagnosis of Clostridium difficile infection
}

\author{
Martina Neuendorf, Raquel Guadarrama-Gonzalez, Birgit Lamik and Colin R. MacKenzie* (1)
}

\begin{abstract}
Background: New molecular methods of detecting Clostridium difficile infection (CDI) provide the routine lab with a sensitive random access method to produce results that are available in a shorter time than traditional methods.

Methods: In this prospective study a total of 989 stool specimens were tested over a period of 16 months in parallel using two isothermal amplification assays, Amplivue ${ }^{\circledast}$ (Quidel) and Illumigene ${ }^{\circledast}$ (Meridian) and the results compared to those from toxigenic culture. In addition all specimens were tested using a cytotoxic cell neutralisation assay (CCNA) and three different Real-time PCR targeting a $C$. difficile-specific $16 \mathrm{~S}$ rDNA sequence or the toxin genes $t c d A$, $t c d B$ / tcdB027 or cdtB.

Results: AmpliVue ${ }^{\oplus}$ was positive in 242 (24.5\%) and Illumigene ${ }^{\oplus}$ in 228 (23.1\%) specimens. 167 (16.9 \%) specimens were positive in toxigenic culture. Real-time-tcdA and -tcdB PCR was positive in 211 (21.3\%) specimens, Real-time-cdtB PCR was positive in 101 (10.2\%) specimens and C. difficile-PCR (16S rDNA) in 267 (27.0\%) specimens.
\end{abstract}

Conclusions: The respective sensitivity, specificity, positive predictive value and negative predictive value compared to toxigenic culture were 91, 89, 62 and $98 \%$ for AmpliVue ${ }^{\circledast}$ and 91, 91, 67 and $98 \%$ for Illumigene ${ }^{\oplus}$.

Keywords: Clostridium difficile, Molecular diagnosis, Isothermal amplification, Real-time PCR, CDI

\section{Background}

Clostridium difficile infection (CDI) is the leading cause of health-care associated diarrhoea most frequently associated with antecedent antibiotic therapy. The incidence of CDI in Europe is rising steadily and has considerable influence on patient morbidity and mortality [1]. The clinical presentation varies widely from mild, watery diarrhoea to pseudomembranous colitis, toxic megacolon and sepsis [2] and in addition recurrent $\mathrm{CDI}$ has become a major problem possibly related to binary toxins as virulence factors [3, 4].

Rapid diagnosis forms a cornerstone for patient management and early isolation, and adequate (antibiotic) therapy of infected patients may reduce transmission and disease

\footnotetext{
* Correspondence: colin.mackenzie@hhu.de

Institute of Medical Microbiology and Hospital Hygiene, University Hospital, Heinrich-Heine University, Düsseldorf, Germany
}

severity $[5,6]$. The laboratory detection of Clostridium difficile is increasingly focused on toxin detection as routine toxigenic culture has a long turnaround time [7]. A C. difficile-specific glutamate dehydrogenase antigen detection assay can be used as a sensitive screening test but has a low specificity and thus requires confirmation, usually by detection of one or both toxin genes [8] or antigen detection using an EIA, which has a low sensitivity. Isothermal amplification assays are easy to use, have low hands on and turnaround times and are highly sensitive [9-12]. European and American guidelines have recommended a two-step testing algorithm for the laboratory diagnosis of CDI consisting of a sensitive antigen test followed by a more specific confirmatory test $[13,14]$ although more recent guidelines have recommended the use of NAATs as stand-alone tests [15]. Due to insufficient data isothermal amplification assays 
have not generally been included in the recommendations concerning NAAT [15]. A recent meta-analysis of published data for loop-mediated isothermal amplification shows the accuracy of this type of isothermal amplification method [9]. The optimal combination of tests is largely dependent on the local conditions and resources. In this large prospective study we compared the performance of two different isothermal amplification assays (AmpliVue, helicase dependant amplification and Illumigene ${ }^{\circ}$, loopmediated isothermal amplification) with toxigenic culture and additionally with an in-house Real-time PCR and cytotoxic cell neutralisation assay in a routine diagnostic laboratory setting.

\section{Methods}

From January 2013 to April 2014 consecutive liquid stool specimens received by the laboratory with a request for $C$. difficile-toxin assay from hospital wards and out-patient departments of three tertiary care hospitals were included in the study and fully evaluated. The persons performing the tests were blinded to the results of the other tests. The study was approved by the ethics committee of the medical faculty of the Heinrich-Heine University of Düsseldorf. Specimens were tested by two commercial isothermal amplification assays, toxigenic culture (TC), cytotoxic cell neutralisation assay (CCNA) and by Real-time PCR (Real-time-tcd PCR) targeting gene sequences for toxin A, B, and B027 (a sequence incorporating a mutation found in the $t c d B$ gene in ribotype 027 strains), binary toxin B (Real-time- $c d t B$ PCR) and a $C$. difficile-specific 16S fragment (Real-time-16S PCR). In previous work we found no $C$. difficile strains with discordant $c d t A$ and $c d t B$ results and thus the $c d t B$ gene was used as a marker for the presence of both binary toxin genes (unpublished data). Sequencing of the $\operatorname{slp} A$ gene was performed on all available $C$. difficile isolates. The reference method was toxigenic culture.

All specimens were tested according to the manufacturers' instructions within $48 \mathrm{~h}$ after delivery to the laboratory. If necessary the specimens were stored at $4{ }^{\circ} \mathrm{C}$ until testing was performed. In brief, the Illumigene ${ }^{\circ}$ assay employs loop-mediated isothermal DNA amplification (LAMP) to detect a gene segment of the $t c d A$ gene in the pathogenicity locus (PaLoc) present in all known toxigenic C. difficile strains. The AmpliVue ${ }^{\bullet}$ assay utilizes helicasedependant amplification (HDA) for the detection of a conserved sequence of the $t c d A$ gene. Positive and negative controls for both assays were provided by the manufacturers and were performed weekly. All stool specimens were cultured for $C$. difficile by inoculating a portion of the stool sample onto Clostridium difficile selective agar (bioMérieux, Germany) and incubating under anaerobic conditions for $48 \mathrm{~h}$. Growth of colonies suspected to be C. difficile were identified by MALDI-ToF (Vitek ${ }^{\bullet}$ MS,
bioMérieux, Germany). C. difficile isolates were stored in glycerine stocks at $-80{ }^{\circ} \mathrm{C}$ and re-cultured on blood agar for $\operatorname{slp} A$ sequencing.

CCNA was performed by re-suspending approximately $100 \mu \mathrm{l}$ of fresh stool in $500 \mu \mathrm{l}$ normal saline and centrifuging at $850 \mathrm{~g}$ for $1 \mathrm{~min}$. Thereafter the supernatant was passed through a $0.2 \mu \mathrm{m}$ filter and $50 \mu \mathrm{L}$ of two dilutions, 1:5 and 1:50 in sterile normal saline, added in duplicate to four wells containing a monolayer of BGM (Buffalo Green Monkey) cells (Sigma-Aldrich, Munich). To one well of each dilution polyclonal anti-toxin antibody was added (Techlab, Blacksberg, USA). A cytopathic effect only in the well without anti-toxin was interpreted as a positive result. Toxigenic culture was performed by adding $C$. difficile culture supernatant to the CCNA instead of stool and results were interpreted in a similar procedure.

DNA extraction from stool specimens was performed by mixing approximately $10 \mu \mathrm{l}$ of the stool specimen in $500 \mu \mathrm{l} \mathrm{PBS}$ and centrifuging at $850 \mathrm{~g}$ for $1 \mathrm{~min}$. A $200 \mu \mathrm{l}$ aliquot of the supernatant was extracted using the DNA tissue kit and EZ1 BioRobot (Qiagen, Germany) and eluted in $100 \mu$ l. The eluates were kept at $-20{ }^{\circ} \mathrm{C}$ until tested.

For $\operatorname{slp} A$ sequencing $2.5 \mu \mathrm{l}$ DNA eluate was added to $1 \mu \mathrm{l}$ Peqgold Hot-Start mastermix (Peqlab, Erlangen), $20.5 \mu \mathrm{l}$ distilled water and $1 \mu \mathrm{l}(3 \mu \mathrm{M})$ primers slpA 19 and slpA 22 (Table 1). The PCR was performed on an Eppendorf Mastercycler pro thermocycler (Wesseling-Berzdorf, Germany) as follows: $95^{\circ} \mathrm{C}$ for 5 min and subsequently 35 cycles comprising $95{ }^{\circ} \mathrm{C}$ for $20 \mathrm{~s}$ and $55^{\circ} \mathrm{C}$ for $180 \mathrm{~s}$, then incubation at $74{ }^{\circ} \mathrm{C}$ for $30 \mathrm{~s}$. A final step at $74{ }^{\circ} \mathrm{C}$ for 5 min completed the PCR. The amplified DNA was sequenced by the Sanger method in the university molecular biology core facility (BMFZ, Biologisch-Medizinisches Forschungzentrum).

For all Real-time PCRs the mastermix per specimen was composed of $12.5 \mu$ l Qiagen Mastermix and $2.5 \mu \mathrm{l}$ $(3 \mu \mathrm{M})$ each of forward and reverse primers (Table 1), $2.5 \mu \mathrm{l}$ probe and $2.5 \mu \mathrm{l} \mathrm{H} \mathrm{H}_{2} \mathrm{O} .2 .5 \mu \mathrm{l}$ from the DNA-eluate were added to the mastermix and heated at $50{ }^{\circ} \mathrm{C}$ for $10 \mathrm{~min}$ and then $95{ }^{\circ} \mathrm{C}$ for $10 \mathrm{~min}$ and thereafter placed in a thermocycler (BioRad, München) for 44 cycles comprising $95^{\circ} \mathrm{C}$ for $15 \mathrm{~s}$ and $60{ }^{\circ} \mathrm{C}$ for $60 \mathrm{~s}$.

The sequences for the primers and probes for the Real-time PCR and $\operatorname{slp} A$ analysis are shown in Table 1.

\section{Results}

A total of 989 stool specimens from 828 patients were included in the study. The number of positive specimens in toxigenic culture was 167 (17\%). The AmpliVue assay was positive in $242(25 \%)$ specimens and Illumigene assay in 228 (23 \%) specimens. Real-time-tcd PCR was positive in $211(21 \%)$ specimens (of these 79 (8\%) were 
Table 1 Primers and probes

\begin{tabular}{|c|c|c|c|c|}
\hline Gene & Primers/Probes & PCR-product (bp) & Acc-number & Gene region $(b p)$ \\
\hline \multirow[t]{3}{*}{$\mathrm{tcdA}$} & tcdA F: 5-'ATTCCAATACAAGYCCTGTAGAAAA-3' & 85 & AM180355 & $796102-796186$ \\
\hline & tcdA R: 5- TITATGTATTCAAGARCAATATCACTGACT-3' & & & \\
\hline & tcdA-S: 5'Fam-RATTTACATTTGTATGGATAGGTGGAG-BHQ-1-3' & & & \\
\hline \multirow[t]{3}{*}{$\mathrm{tcdB}$} & tcdBF: 5'-AACAGGTGTATTTAGTACAGAAGATGGATT-3' & 85 & AM180355 & $793077-793161$ \\
\hline & tcdBR: 5'-AATTGCTTCTCCTTCTAGGTTTTCAT-3' & & & \\
\hline & tcdB-S: 5'-Hex-AAATATTTTGCCCCAGCTAATACACTT-BHQ-1-3' & & & \\
\hline \multirow[t]{3}{*}{$\operatorname{tcdB027^{a}}$} & tcdBF: 5'-AACAGGTGTATTTAGTACAGAAGATGGATT-3' & 85 & FN665654 & 708928-709012 \\
\hline & 027tcdBR*: 5'-AATTGCTTCCCCCTCTAGATTTTCAT-3' & & & \\
\hline & 027tcdB-S:5'-Hex-AAATATTITGCTCCAGCAGATACACTT-BHQ-1-3' & & & \\
\hline \multirow[t]{3}{*}{$16 S$} & CdF: 5'-TGTACACACGGATAACATACCGAAA-3' & 131 & AM180355 & $125189-125289$ \\
\hline & CdR:5'-CCGTTACCTTACCAACTAGCTAATCA-3' & & & \\
\hline & CdS5'-Fam-CATCTCTTGAATATCAAAGGTGAGCCAGTACAGG-BHQ-1-3' & & & \\
\hline \multirow[t]{3}{*}{$c d t B$} & cdtBfor: 5'GATGATCCATTTATCCCAAATAACAA-3' & 132 & FN665654 & $2833044-2833175$ \\
\hline & cdtBrev:5'GTCCTTAATAGTATATCCATTTCGTTCATATG-3' & & & \\
\hline & cdtBS:5'Hex-TTCTITGACCCAAAGTTGATGTCTGATTGGG-BHQ-1-3' & & & \\
\hline \multirow[t]{2}{*}{ slpA (Kato et al. 2004) } & slpAcom22 : 5'-GCWGTYTCTATTCTATCDTYWCC-3' & 23 & AM180355 & $3253526-3254737$ \\
\hline & slpAcom19: 5'-GTTGGGAGGAATTAAGRAAtG-3' & 22 & & \\
\hline
\end{tabular}

${ }^{\mathrm{a} B o l d e d}$ bases represent a difference from the standard $t c d B$ primer or probe

positive for the tcdB027 gene) and C. difficile-16S-PCR was positive in $267(27 \%)$ specimens.

Isothermal amplification assay results discrepant to toxigenic culture are shown in Tables 2 and 3. A total of 90 (9\%) specimens tested with AmpliVue and 75 (8\%) specimens tested with Illumigene ${ }^{\circ}$ were positive by isothermal amplification but negative in the toxigenic culture (i. e. false positive). Sixty three of these specimens were positive in both isothermal amplification methods. On the other hand 15 (2\%) specimens tested with AmpliVue and 14 (1\%) specimens tested with Illumigene ${ }^{\circ}$ were negative in isothermal amplification but positive in the toxigenic culture (i. e. false negative). Of these 12 specimens were negative in both isothermal amplification assays. C. difficile strains in which no toxin production was detected in bacterial culture supernatants were classified non-toxigenic strains. 20 of 34 stool specimens containing non-toxigenic strains were positive in the AmpliVue assay and 19 strains were positive in the Illumigene ${ }^{\circ}$ assay. The respective sensitivity, specificity, positive predictive value (PPV) and negative predictive value (NPV) for the isothermal amplification assays compared to toxigenic culture were $91,89,62$ and $98 \%$ for AmpliVue $^{\circ}$ and 91, 91, 67 and $98 \%$ for Illumigene ${ }^{\circ}$. The sensitivity, specificity, PPV and NPV for Real-time $t c d$ PCR compared to toxigenic culture were $91,93,73$ and $98 \%$ respectively.

For general epidemiological purposes and to determine if there was any correlation between strain type and the results of isothermal amplification or toxigenic culture all cultures were typed by $\operatorname{slpA}$-sequencing. Of the $C$. difficile strains 171 were typable by $\operatorname{slp} A$ sequencing the distribution of which is shown in Fig. 1. Three $\operatorname{sip} A$ types made up the majority (69\%) of the strains: the most common slpA type was gc8 (63 specimens, $37 \%$ ) (associated with ribotype 027 [16]); followed by gr (29

Table 2 Discrepant results for isothermal amplification: false positive specimens

\begin{tabular}{|c|c|c|c|c|c|c|}
\hline $\mathrm{N}$ & AmpliVue & |llumigene ${ }^{\circledast}$ & Culture & $\mathrm{TC}$ & Real-time-tcd PCR & $16 S$ PCR \\
\hline 17 & + & + & + & - & + & + \\
\hline 1 & + & + & + & - & - & + \\
\hline 30 & + & + & - & - & + & + \\
\hline 4 & + & + & - & - & - & + \\
\hline 11 & + & + & - & - & - & - \\
\hline 1 & + & - & + & - & - & + \\
\hline 1 & + & - & - & - & + & + \\
\hline 3 & + & - & - & - & - & + \\
\hline 18 & + & - & - & - & - & - \\
\hline 1 & - & + & + & - & + & + \\
\hline 2 & - & + & - & - & + & + \\
\hline 8 & - & + & - & - & - & - \\
\hline 1 & + & invalid & + & - & + & + \\
\hline 1 & + & invalid & - & - & - & + \\
\hline 1 & + & invalid & - & - & + & + \\
\hline 1 & + & invalid & - & - & - & - \\
\hline 1 & Invalid & + & - & - & - & - \\
\hline
\end{tabular}

TC, toxigenic culture 
Table 3 Discrepant data for isothermal amplification: false negative specimens

\begin{tabular}{llllll}
\hline $\mathrm{N}$ & AmpliVue $^{\oplus}$ & Illumigene $^{\oplus}$ & $\mathrm{TC}$ & Real-time-tcd PCR & Real-time 16S PCR \\
\hline 1 & - & - & + & + & + \\
2 & - & - & + & - & + \\
9 & - & - & + & - & - \\
2 & - & + & + & - & + \\
1 & - & + & + & + & + \\
2 & + & - & + & + & + \\
\hline
\end{tabular}

$\mathrm{TC}$, toxigenic culture

specimens, $17 \%$; 27 of which were gr-01 and 2 were gr04) and hr (25 specimens, $15 \%$; 19 of which were hr-01, 4 were hr-02, 1 was hr-05 and 1 was hr-06). 8 (5 \%) specimens were typed as $078-01$ or $\mathrm{kr} 03$. All other $\operatorname{slp} A$ types were represented by less than 8 specimens each. 14 specimens of the 171 specimens analysed by $\operatorname{slp} A$ sequencing were atoxigenic as they were neither positive in $\mathrm{TC}$ nor in Real-time-tcd PCR. Atoxigenic $\operatorname{slp} A$ types were $\mathrm{xr}$ and 078 (3 specimens each) and one strain each was nc, cr, ac, fr. Of the 79 specimens positive in the $t c d B 027$ Real-time PCR 61 specimens were available for slpA-typing. 57 (93\%) of these specimens were type gc8 and of 63 gc8 types 57 (90\%) were $t c d B 027$-positive.

The binary toxin gene ( $c d t B$-PCR) was detected in 87 specimens. A correlation between Real-time $t c d B 027$ PCR and $c d t B$ PCR positivity was high (70 of the 87 binary toxin positive specimens (80\%) were Real-time-tcdB027 PCR positive).

\section{Discussion}

To our knowledge this is the largest reported study comparing the isothermal amplification assays from AmpliVue and Illumigene ${ }^{\oplus}$ with a Real-time PCR in reference to toxigenic culture. A study reported by Deak et al. directly comparing the AmpliVue assay and a Real-time PCR assay by Simplexa ${ }^{\oplus}$ (Simplexa ${ }^{\mathrm{TM}}$, Focus Diagnostics) with the

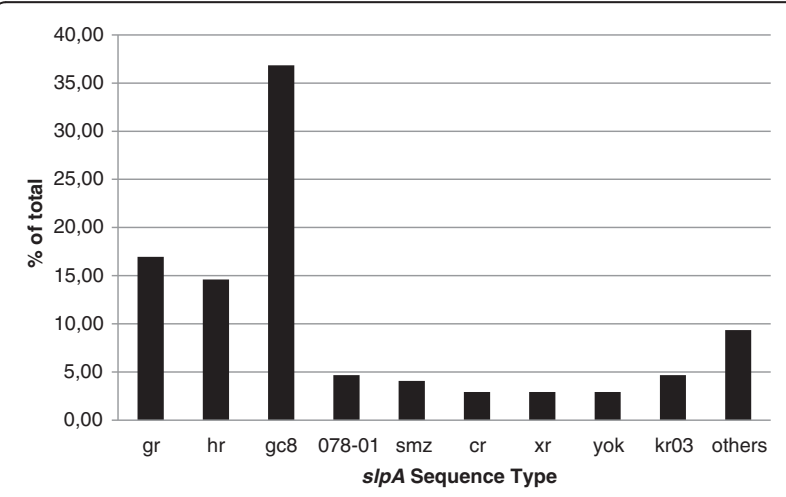

Fig. 1 Prevalence of slpA types in the study isolates. All cultures were subjected to typing by determining the slpA sequence as described in the methods
Illumigene ${ }^{\odot}$ assay in a sample size of 200 found a sensitivity and specificity of $96 \%$ and $100 \%$. Other recent studies with a lower number of specimens using $\mathrm{TC}$ as reference method have also revealed high sensitivities and specificities for AmpliVue ${ }^{\bullet}$ and Illumigene ${ }^{\bullet}[10-12,17,18]$.

In general molecular tests have many advantages: They are easy to perform and often associated with high sensitivity and specificity. Nevertheless there are some disadvantages. Firstly, the assays are performed in stool containing a large amount of extraneous DNA which may interfere with the detection [11]. Recent studies however have not shown much cross reactivity $[19,20]$. Secondly, the mere presence of toxin genes is not proof of toxin expression. Therefore only patients with an appropriate clinical suspicion of CDI should be tested by the laboratory $[11,21]$ since the carriage of $C$. difficile, even toxigenic strains, is not necessarily diagnostic of disease or in itself an indication for therapy $[22,23]$. In settings with a low prevalence of CDI the low positive predictive value of the isothermal tests as shown in this study may lead to a rather high number of laboratory diagnoses of CDI, in which perhaps another cause for the diarrhoea is present. This is especially important in clinically complicated cases, in which multiple factors may be relevant.

The relatively low PPV in our study compared to that of Hong et al. may possibly be due to a lower sensitivity of the reference method in our study. The number of specimens positive in 16S-PCR (106) that were $C$. difficile culture-negative would support this hypothesis, however the detection of DNA from $C$. difficile alone does not necessarily relate to the presence of viable bacteria and since the CCNA was negative in all these cases it would seem probable that if indeed bacteria were present and viable, they were not producing significant amounts of toxin and therefore not causing CDI. This raises the important question as to the clinical usefulness of such highly sensitive methods to detect CDI and if NAAT methods may in fact not overcall CDI. A contrary view is that since CDI is thought to be essentially underdiagnosed $[24,25]$, the high sensitivity of isothermal amplification assays may contribute to a better detection of disease.

In 34 (3.4\%) specimens the toxigenic culture was negative despite a positive culture for $C$. difficile indicating non toxin-producing strains. In comparison the Real-time-tcd PCR was positive in 56 cases, in which toxigenic culture was negative resulting in a specificity and PPV of 93 and $73 \%$. According to Buchan et al. false positive results can occur due to the presence of non-viable bacteria or residual DNA or because the isothermal amplification tests have a lower level of detection than toxigenic culture (i. e. true positive). As a control in their study they used another PCR targeting a different region of the $C$. difficile chromosome than that targeted by the isothermal amplification assay, the results of which confirmed the results of the 
latter. This would support the purported higher sensitivity of the isothermal amplification assay [26]. Following this argument the performance of the isothermal amplification assays in terms of true specificity and PPV would be better if the reference method in our study was more sensitive.

In the present study we found only one minor difference between the two isothermal assays: A higher number of invalid results (26 specimens) were obtained using the Illumigene ${ }^{\circ}$ assay; whereas only 11 specimens were invalid using the AmpliVue ${ }^{\circ}$ assay. The relatively high number of non-evaluable tests using Illumigene ${ }^{\circ}$ was due to sample overloading at the beginning of the study period, which improved with experience and in the latter half of the study was negligible. Furthermore Illumigene ${ }^{\circ}$ invalid results are known to be caused by blood-containing samples $[27,28]$. In this study very few patients presented with bloody diarrhoea (data not shown). However we were able to confirm this in 2 macroscopically bloody samples. This would be a disadvantage of the assay for patients with severe CDI and bloody stools unless an additional DNApurification step is added prior to testing.

To evaluate the practicality of the isothermal amplification assays the number of steps, hands on time and turnaround time were determined. Both are equivalent in terms of practicality in the routine laboratory. Each assay had 6 (Illumigene ${ }^{\circ}$ ) and 7 (AmpliVue ${ }^{\circ}$ ) steps with hands on time for 10 specimens of 14 min (Illumigene ${ }^{\circ}$ ) and $12 \mathrm{~min}$ (AmpliVue ${ }^{\circ}$ and total turnaround time was 64 and 92 min respectively.

\section{Conclusion}

This study contributes data towards the determination of the value of isothermal amplification as a diagnostic tool for CDI. Both isothermal methods are easy to use, deliver reliable results with a rapid turn-around time and have a high sensitivity compared to other molecular methods. A high negative predictive value of $98 \%$ was demonstrated for both assays, which provides a rapid reliable result to clinicians treating patients with suspected CDI and diarrhoea enabling a de-escalation of empiric therapy. For laboratories dealing with a small number of CDI-requests the option of a single step random access diagnostic method in terms of personnel efficiency is probably cost effective. Both tests are useful for the detection of $C$. difficile with up to 10 specimens per run.

\footnotetext{
Abbreviations

BGM: Buffalo Green Monkey; CDI: Clostridium difficile infection; CCNA: cytotoxic cell neutralisation assay; EIA: enzyme immunoassay; HDA: helicase-dependant amplification; LAMP: loop-mediated isothermal DNA amplification; MALDI-ToF: Matrix-assisted-laser desorption/ionisationtime of flight; NAAT: nucleic acid amplification test; PaLoc: pathogenicity locus; TC: toxigenic culture.
}

\section{Competing interests}

The authors declare that they have no conflict of interests regarding the performance of the study or publication of the results.

\section{Authors' contributions}

MB performed all experiments, designed the study and wrote the manuscript, RG-G and BL performed some of the molecular assays and CM designed the study and wrote the manuscript. All authors read and approved the final manuscript.

\section{Acknowledgements}

We would like to thank Ilona Widera and Dilek Kara, for their excellent technical assistance. This work was performed in collaboration with the ESCMID Study Group on Molecular Diagnostics (ESGMD), Basel, Switzerland.

Received: 21 July 2015 Accepted: 3 February 2016

Published online: 12 February 2016

References

1. Smith AM, Wuerth BA, Wiemken TL, Arnold FW. Prevalence of Clostridium difficile infection presenting to US EDs. Am J Emerg Med. 2015;33(2):238-43.

2. Walters PR, Zuckerbraun BS. Clostridium difficile infection: clinical challenges and management strategies. Crit Care Nurse. 2014;34(4):24-34. quiz 35.

3. Stewart DB, Berg A, Hegarty J. Predicting recurrence of $C$. difficile colitis using bacterial virulence factors: binary toxin is the key. J Gastrointest Surg. 2013;17(1):118-24. discussion p.124-115.

4. Bacci S, Mølbak K, Kjeldsen MK, Olsen KE. Binary toxin and death after Clostridium difficile infection. Emerg Infect Dis. 2011;17(6):976-82.

5. Hardy K, Manzoor S, Marriott C, Parsons H, Waddington C, Gossain S, et al. Utilizing rapid multiple-locus variable-number tandem-repeat analysis typing to aid control of hospital-acquired Clostridium difficile Infection: a multicenter study. J Clin Microbiol. 2012;50(10):3244-8.

6. Bentley AH, Patel NB, Sidorczuk M, Loy P, Fulcher J, Dexter P, et al. Multicentre evaluation of a commercial test for the rapid diagnosis of Clostridium difficile-mediated antibiotic-associated diarrhoea. Eur J Clin Microbiol Infect Dis. 1998;17(11):788-90.

7. Bartlett JG, Gerding DN. Clinical recognition and diagnosis of Clostridium difficile infection. Clin Infect Dis. 2008;46 Suppl 1:S12-8.

8. Fenner L, Widmer AF, Goy G, Rudin S, Frei R. Rapid and reliable diagnostic algorithm for detection of Clostridium difficile. J Clin Microbiol. 2008;46(1):328-30.

9. Lloyd A, Pasupuleti V, Thota P, Pant C, Rolston DD, Hernandez AV, et al. Accuracy of loop-mediated isothermal amplification for the diagnosis of Clostridium difficile infection: a systematic review. Diagn Microbiol Infect Dis. 2015:82(1):4-10.

10. Deak E, Miller SA, Humphries RM. Comparison of Illumigene, Simplexa, and AmpliVue Clostridium difficile molecular assays for diagnosis of C. difficile infection. J Clin Microbiol. 2014;52(3):960-3.

11. Eckert C, Holscher E, Petit A, Lalande V, Barbut F. Molecular test based on isothermal helicase-dependent amplification for detection of the Clostridium difficile toxin A gene. J Clin Microbiol. 2014;52(7):2386-9.

12. Norén T, Unemo M, Magnusson C, Eiserman M, Matussek A. Evaluation of the rapid loop-mediated isothermal amplification assay Illumigene for diagnosis of Clostridium difficile in an outbreak situation. APMIS. 2014; 122(2):155-60.

13. Debast SB, Bauer MP, Kuijper EJ, Diseases ESoCMal. European Society of Clinical Microbiology and Infectious Diseases: update of the treatment guidance document for Clostridium difficile infection. Clin Microbiol Infect. 2014;20 Suppl 2:1-26.

14. Cohen SH, Gerding DN, Johnson S, Kelly CP, Loo VG, McDonald LC, et al. Clinical practice guidelines for Clostridium difficile infection in adults: 2010 update by the society for healthcare epidemiology of America (SHEA) and the infectious diseases society of America (IDSA). Infect Control Hosp Epidemiol. 2010;31(5):431-55.

15. Surawicz CM, Brandt LJ, Binion DG, Ananthakrishnan AN, Curry SR, Gilligan $\mathrm{PH}$, et al. Guidelines for diagnosis, treatment, and prevention of Clostridium difficile infections. Am J Gastroenterol. 2013;108(4):478-98. quiz 499.

16. Kato H, Kato H, Ito Y, Akahane T, Izumida S, Yokoyama T, et al. Typing of Clostridium difficile isolates endemic in Japan by sequencing of slpA and its application to direct typing. J Med Microbiol. 2010;59(Pt 5):556-62.

17. Ylisiurua P, Koskela M, Vainio O, Tuokko H. Comparison of antigen and two molecular methods for the detection of Clostridium difficile toxins. Scand J Infect Dis. 2013;45(1):19-25.

18. Hong G, Park KS, Ki CS, Lee NY. Evaluation of the illumigene C. difficile assay for toxigenic Clostridium difficile detection: a prospective study of 302 
consecutive clinical fecal samples. Diagn Microbiol Infect Dis. 2014:80(3):177-80.

19. Couturier B, Schlaberg R, Konzak C, Nicholes J, Law C, She RC. tcdA As a diagnostic target in a loop-mediated amplification assay for detecting toxigenic Clostridium difficile. J Clin Lab Anal. 2013;27(3):171-6.

20. Kaltsas A, Simon M, Unruh LH, Son C, Wroblewski D, Musser KA, et al. Clinical and laboratory characteristics of Clostridium difficile infection in patients with discordant diagnostic test results. J Clin Microbiol. 2012;50(4):1303-7.

21. Dubberke ER, Han Z, Bobo L, Hink T, Lawrence B, Copper S, et al. Impact of clinical symptoms on interpretation of diagnostic assays for Clostridium difficile infections. J Clin Microbiol. 2011;49(8):2887-93.

22. Lubbert C, John E, von Muller L. Clostridium difficile infection: guideline-based diagnosis and treatment. Dtsch Arztebl Int. 2014;111(43):723-31.

23. Gerding DN, Brazier JS. Optimal methods for identifying Clostridium difficile infections. Clin Infect Dis. 1993;16 Suppl 4:S439-42.

24. Davies KA, Longshaw CM, Davis GL, Bouza E, Barbut F, Barna Z, et al. Underdiagnosis of Clostridium difficile across Europe: the European, multicentre, prospective, biannual, point-prevalence study of Clostridium difficile infection in hospitalised patients with diarrhoea (EUCLID). Lancet Infect Dis. 2014;14(12):1208-19.

25. Barbut F, Rame L, Petit A, Suzon L, de Chevigny A, Eckert C, et al. Prevalence of Clostridium difficile infection in hospitalized patients with diarrhea: results of a French prospective multicenter bi-annual point prevalence study. Presse Med. 2015:44(4 Pt 1):e75-83.

26. Buchan BW, Mackey TL, Daly JA, Alger G, Denys GA, Peterson LR, et al. Multicenter clinical evaluation of the portrait toxigenic $\mathrm{C}$. difficile assay for detection of toxigenic Clostridium difficile strains in clinical stool specimens. J Clin Microbiol. 2012;50(12):3932-6

27. McElgunn CJ, Pereira CR, Parham NJ, Smythe JE, Wigglesworth MJ, Smielewska A, et al. A low complexity rapid molecular method for detection of Clostridium difficile in stool. PLoS One. 2014;9(1):e83808.

28. Pancholi P, Kelly C, Raczkowski M, Balada-Llasat JM. Detection of toxigenic Clostridium difficile: comparison of the cell culture neutralization, Xpert C. difficile, Xpert C. difficile/Epi, and Illumigene C. difficile assays. J Clin Microbiol. 2012:50(4):1331-5.

\section{Submit your next manuscript to BioMed Central and we will help you at every step:}

- We accept pre-submission inquiries

- Our selector tool helps you to find the most relevant journal

- We provide round the clock customer support

- Convenient online submission

- Thorough peer review

- Inclusion in PubMed and all major indexing services

- Maximum visibility for your research

Submit your manuscript at www.biomedcentral.com/submit

) Biomed Central 